\title{
Inhibition of Fish Pathogenic Aeromonas hydrophila and Edwardsiella tarda by Centella asiatica In-vitro
}

\author{
Soumyadip Purkait ${ }^{1 *}$, Thangapalam Jawahar Abraham², Sutanu Karmakar ${ }^{3}$, Biswadeep Dey² and Anwesha Roy² \\ ${ }^{1}$ Department of Fishery Economics and Statistics, Faculty of Fishery Sciences, West Bengal University of Animal and Fishery Sciences, Kolkata, India \\ ${ }^{2}$ Department of Aquatic Animal Health, Faculty of Fishery Sciences, West Bengal University of Animal and Fishery Sciences, Kolkata, India \\ ${ }^{3}$ Aquatic Environment and Health Management Division, ICAR-Central Institute of Fisheries Education, Mumbai, India
}

\begin{abstract}
The present study assessed the in-vitro inhibition of fish pathogenic bacteria, viz., Aeromonas hydrophila and Edwardsiella tarda by aqueous, methanol and chloroform extracts of Centella asiatica by agar-disc diffusion, agar overlay well-diffusion, and broth dilution assays. The agar-disc diffusion assay with $10 \mu \mathrm{L}$ of sterile crude $C$. asiatica extracts failed to inhibit $A$. hydrophila; while the crude chloroform extract inhibited $E$. tarda $(11.25 \pm 0.35 \mathrm{~mm})$. In agar overlay well-diffusion assay, the methanol and chloroform extracts of $C$. asiatica $(50 \mu \mathrm{L})$ inhibited $E$. tarda at varying levels exhibiting zones of $7.50 \pm 0.70 \mathrm{~mm}$ and $30.50 \pm 6.40 \mathrm{~mm}$, respectively. With the increasing concentration of crude chloroform $C$. asiatica extract $(0-10 \% / \mathrm{mL})$, an increased growth inhibition of $E$. tarda was noted in broth dilution assay. These results demonstrated that the chloroform extract of $C$. asiatica has the highest antibacterial activity against $E$. tarda in-vitro, which can be applied as an alternative to the commercial antibiotic to control $E$. tarda infection in aquaculture.
\end{abstract}

Keywords: Centella asiatica; Chloroform extract; Antimicrobial activity; In-vitro assay; Growth inhibition

\section{Introduction}

Fish diseases cause a huge economic loss in the aquaculture sector. Out of them, bacterial diseases are the most important cause of losses $[1,2]$. Aeromonas hydrophila is an opportunistic Gram-negative bacterial pathogen, which is prevalent in aquatic habitats with cosmopolitan distribution and has resulted in heavy mortalities in farmed and feral fish [1]. Edwardsiella tarda is a zoonotic Gram-negative bacterial pathogen, which can infect a variety of animals including mammals, amphibians, reptiles and fish. It has a worldwide distribution and can be found in pond water, mud, and the intestine of fish and other marine animals [2]. These pathogens are being controlled by antibiotics. However, considering the inherent negative effects of antibiotics, other alternative antimicrobials from plant origins are increasingly used in aquaculture [3]. Since prehistoric times, herbs were the basis for nearly all medicinal therapy until synthetic drugs were developed in the $19^{\text {th }}$ century [4]. Medicinal plants have many traditionally reported properties including the treatment of ailments of infectious origin. Antimicrobial properties of medicinal herbs are increasingly reported from different parts of the world [5]. Among many herbs having antimicrobial activity, the members belonging to Apocynaceae and Lamiaceae are considered as the most effective against pathogens [6]. Centella asiatica, also known as Asiatic pennywort or Gotu kola or Indian pennywort, is a perennial herbaceous plant belonging to the family Apiaceae, subfamily Mackinlayoideae [7]. It is used as antibacterial, anti-inflammatory, antidiabetic, antioxidant and antifungal [8]. It is also recommended for wound healing, improving blood circulation, strengthening the veins, revitalising the nerve and brain cells, increasing the memory and concentration, bringing down the fever and treating dysentery, diarrhoea and skin diseases [9]. The active compounds in C. asiatica are many types of terpenes or terpenoids. It showed a promising antibacterial effect against Bacillus cereus and Listeria monocytogenes under normal and osmotic stress [10] and other human bacterial pathogens [11-13]. An earlier study has shown the potentialities of medicinal herbs in controlling certain fish pathogens [14]. This study assessed the antimicrobial activity of $C$. asiatica extracts against fish pathogenic bacteria like Aeromonas hydrophila and Edwardsiella tarda.

\section{Materials and Methods}

Fresh leaves (Figure 1a) of C. asiatica were collected from the Faculty of Fishery Sciences, West Bengal University of Animal and Fishery Sciences, Kolkata, India $\left(22^{\circ} 47^{\prime} \mathrm{N}, 88^{\circ} 40^{\prime} \mathrm{E}\right)$. The leaves were thoroughly washed in running water and air-dried. The leaves were then dried in hot-air oven at $50^{\circ} \mathrm{C}$ for 24 hours, ground to a fine powder and sieved $(\phi: 0.9 \mathrm{~mm})$. The sieved samples (Figure $1 \mathrm{~b})$ were subsequently soaked separately in water and organic solvents, viz., methanol and chloroform for two days with continuous shaking at $200 \mathrm{rpm}$ at $30^{\circ} \mathrm{C}$. The extracts of each solvent were filtered twice using Whatman No.1 filter paper. The filtrates were concentrated, filter sterilized through a $0.45-\mu \mathrm{m}$ membrane filter and stored at $-20^{\circ} \mathrm{C}$ until further use. The fish pathogenic bacterial strains, viz., Aeromonas hydrophila (NCBI accession number KC914628) and Edwardsiella tarda (NCBI accession number KF853565) were from the collections of the Department of Aquatic Animal Health, Faculty of Fishery Sciences, Kolkata. Unless otherwise stated, the bacteria were routinely maintained aerobically on brain heart infusion agar [BHIA] or broth [BHIB] (HiMedia, India) at $30^{\circ} \mathrm{C}$

The agar-disc diffusion assay was performed using $18 \mathrm{~h}$ culture of A. hydrophila $\left(2.35 \times 10^{9} \mathrm{CFU} / \mathrm{mL}\right)$ and E. tarda $\left(1.28 \times 10^{9} \mathrm{CFU} / \mathrm{mL}\right)$ at $30^{\circ} \mathrm{C}$. The bacterial lawn was prepared by spreading the cell suspension using a sterile cotton swab on Mueller-Hinton Agar [MHA] (HiMedia, India) in order to get a uniform bacterial growth [15]. Sterile discs

*Corresponding author: Soumyadip Purkait, Department of Fishery Economics and Statistics, Faculty of Fishery Sciences, West Bengal University of Animal and Fishery Sciences, Kolkata, Tel: +918100573134 E-mail: soumyadippurkait07@gmail.com

Received January 23, 2018; Accepted February 24, 2018; Published February 27,2018

Citation: Purkait S, Abraham TJ, Karmakar S, Dey B, Roy A (2018) Inhibition of Fish Pathogenic Aeromonas hydrophila and Edwardsiella tarda by Centella asiatica In-vitro. J Aquac Res Development 9: 524. doi: 10.4172/2155-9546.1000524

Copyright: ( 2018 Purkait S, et al. This is an open-access article distributed under the terms of the Creative Commons Attribution License, which permits unrestricted use, distribution, and reproduction in any medium, provided the original author and source are credited. 
Citation: Purkait S, Abraham TJ, Karmakar S, Dey B, Roy A (2018) Inhibition of Fish Pathogenic Aeromonas hydrophila and Edwardsiella tarda by Centella asiatica In-vitro. J Aquac Res Development 9: 524. doi: 10.4172/2155-9546.1000524

(HiMedia, India) of $6 \mathrm{~mm}$ diameter were placed onto the seeded MHA and loaded with $10 \mu \mathrm{L}$ of sterile crude aqueous, methanol and chloroform extracts, and their respective control (negative) separately. A chloramphenicol disc ( $30 \mu \mathrm{g} /$ disc; HiMedia, India) was used as a positive control. The plates were incubated at $30^{\circ} \mathrm{C}$ for 24 hours and observed for the zones of inhibition $(\mathrm{mm})$. The soft-agar overlay welldiffusion assay was performed as per Hockett and Baltrus [16]. Briefly, the wells of $5 \mathrm{~mm}$ diameter were made aseptically on deep MHA using a sterile well borer. The bottom of the wells were sealed-off using molten soft BHIA (BHIB $+0.7 \%$ agar). The filtered sterilized extracts $(50 \mu \mathrm{L}$ each) were added into the wells along with their respective solvents as control. The extracts were allowed to diffuse into the medium for 1 hour. The plates were then overlaid with $10 \mathrm{~mL}$ molten soft agar seeded with $10 \mu \mathrm{L}$ of $20 \mathrm{~h}$ old culture of A. hydrophila and E. tarda so

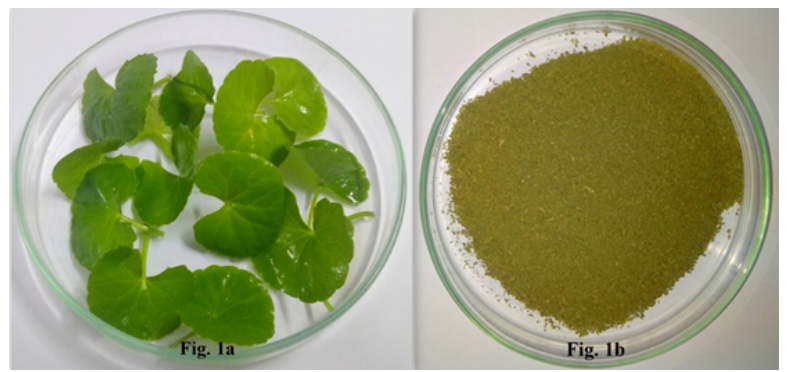

Figure 1: Centella asiatica leaves (a) fresh and (b) after drying, pulverizing and sieving.

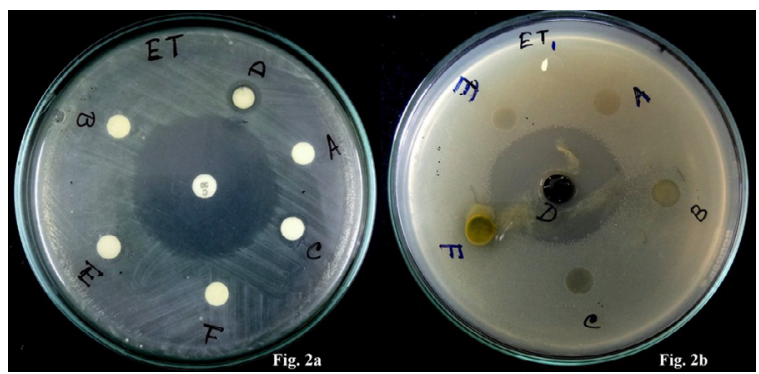

Figure 2: Inhibition of Edwardsiella tarda by (a) agar disc diffusion and (b) agar overlay well-diffusion assays. A: Aqueous control; B: Aqueous test; C: Chloroform control; D: Chloroform test; E: Methanol control; F: Methanol test; C 30: Chloramphenicol, $30 \mu \mathrm{g} / \mathrm{disc}$. The volumes of extracts used were $10 \mu \mathrm{L} / \mathrm{disc}$ and $50 \mu \mathrm{L} /$ well for agar disc diffusion and agar overlay well-diffusion assays respectively.

\begin{tabular}{|c|c|c|c|c|}
\hline \multirow{2}{*}{ Extracts } & \multicolumn{4}{|c|}{ Zone of inhibition (mm) } \\
\cline { 2 - 5 } & \multicolumn{3}{|c|}{ Agar-disc diffusion assay } & $\begin{array}{c}\text { Agar overlay well-diffusion } \\
\text { assay }\end{array}$ \\
\cline { 2 - 5 } & $\begin{array}{c}\text { Aeromonas } \\
\text { hydrophila }\end{array}$ & $\begin{array}{c}\text { Edwardsiella } \\
\text { tarda }\end{array}$ & $\begin{array}{c}\text { Aeromonas } \\
\text { hydrophila }\end{array}$ & $\begin{array}{c}\text { Edwardsiella } \\
\text { tarda }\end{array}$ \\
\hline Aqueous control & $6.00 \pm 0.00^{\mathrm{a}}$ & $6.00 \pm 0.00^{\mathrm{a}}$ & $5.00 \pm 0.00^{\mathrm{a}}$ & $5.00 \pm 0.00^{\mathrm{a}}$ \\
\hline Aqueous test & $6.00 \pm 0.00^{\mathrm{a}}$ & $6.00 \pm 0.00^{\mathrm{a}}$ & $5.00 \pm 0.00^{\mathrm{a}}$ & $5.00 \pm 0.00^{\mathrm{a}}$ \\
\hline Chloroform control & $6.00 \pm 0.00^{\mathrm{a}}$ & $6.00 \pm 0.00^{\mathrm{a}}$ & $5.00 \pm 0.00^{\mathrm{a}}$ & $5.00 \pm 0.00^{\mathrm{a}}$ \\
\hline Chloroform test & $6.00 \pm 0.00^{\mathrm{a}}$ & $11.25 \pm 0.35^{\mathrm{b}}$ & $5.00 \pm 0.00^{\mathrm{a}}$ & $30.50 \pm 6.40^{\mathrm{b}}$ \\
\hline Methanol control & $6.00 \pm 0.00^{\mathrm{a}}$ & $6.00 \pm 0.00^{\mathrm{a}}$ & $5.00 \pm 0.00^{\mathrm{a}}$ & $5.00 \pm 0.00^{\mathrm{a}}$ \\
\hline Methanol test & $6.00 \pm 0.00^{\mathrm{a}}$ & $6.00 \pm 0.00^{\mathrm{a}}$ & $5.00 \pm 0.00^{\mathrm{a}}$ & $7.50 \pm 0.70^{\mathrm{a}}$ \\
\hline Chloramphenicol & $31.75 \pm 1.06^{\mathrm{b}}$ & $40.75 \pm 1.76^{\mathrm{c}}$ & $\mathrm{ND}$ & $\mathrm{ND}$ \\
\hline Datayy
\end{tabular}

Data represent means \pm Standard Deviation; ND: Not Done; ${ }^{a-c}$ Values sharing uncommon superscripts within the column differ significantly $(P<0.05)$

Table 1: In-vitro inhibition of Aeromonas hydrophila and Edwardsiella tarda by the crude extracts of Centella asiatica by agar-disc diffusion and agar overlay welldiffusion assays.

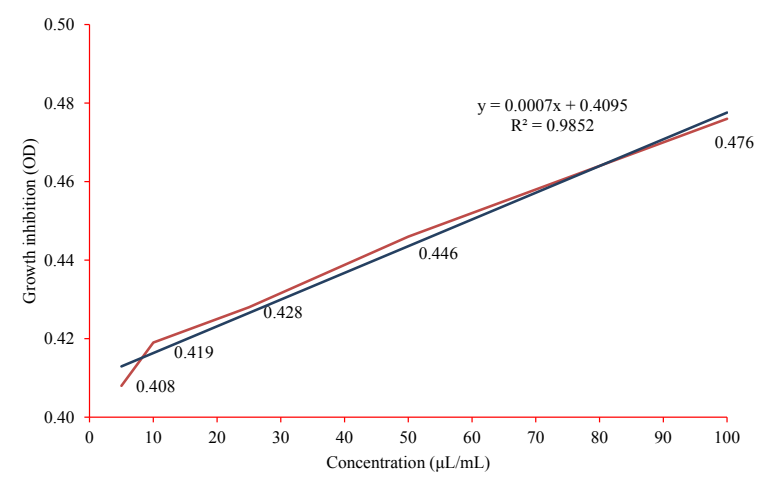

Figure 3: Growth inhibition of Edwardsiella tarda by the crude Centella asiatica chloroform extract in broth dilution assay. [OD: Optical Density].

as to get a concentration of $\sim 10^{6}$ cells $/ \mathrm{mL}$. The plates were incubated for $24 \mathrm{~h}$ at $30^{\circ} \mathrm{C}$ and observed for the zones of inhibition. The growth inhibition of $E$. tarda by the chloroform extract of $C$. asiatica was determined by broth dilution assay [17]. The tubes containing BHIB were supplemented with sterile chloroform extract at concentrations of 0 (control), $0.5 \%, 1.0 \%, 1.5 \%, 2.5 \%, 5 \%, 7.5 \%$ and $10 \%$. The broths were then inoculated with $E$. tarda at about $5 \times 10^{6} / \mathrm{mL}$ level. After incubation at $30^{\circ} \mathrm{C}$ for $24 \mathrm{~h}$, the optical density (OD) was measured at $620 \mathrm{~nm}$ using a UV- visible spectrophotometer. The difference between the OD of the sample and control was interpreted as the inhibitory effect of C. asiatica on E. tarda. The growth inhibition of chloroform extract was determined by plotting the change in the OD against the concentration of $C$. asiatica. The experimental data, presented as the mean \pm standard deviation, were statistically analyzed by one-way ANOVA followed by Duncan's Multiple Range Test using SPSS 16.0 software. The membrane filtered chloroform extract was adjusted to a concentration of $0.1 \mathrm{~g} / \mathrm{mL}$ using sterile chloroform for UV-VIS spectrum analysis. The extract was scanned at wavelength ranging from 400 to $900 \mathrm{~nm}$ using LABINDIA ${ }^{\circ}$ UV 3200 spectrophotometer and the characteristic peaks were detected using UV-Win spectrophotometer software Ver 5.2.0.1104. The peak values of the UV-VIS were recorded.

\section{Results and Discussion}

The results of the in-vitro inhibition of A. hydrophila and E. tarda by the crude extracts of $C$. asiatica by agar-disc diffusion (Figure 2a) and agar overlay well-diffusion assays (Figure $2 \mathrm{~b}$ ) are presented in Table 1. There existed significant differences in the zones of inhibition among the extracts $(\mathrm{P}<0.05)$. The broth dilution assay was performed using the chloroform extract against $E$. tarda and the results of the growth inhibition in terms of optical density are represented in Figure 3. With the increasing concentration of crude chloroform C. asiatica extract, an increased growth inhibition was noted with a $\mathrm{R}^{2}$ value of 0.9852 $(\mathrm{P}<0.05)$. Among the aqueous, methanol and chloroform extracts tried, only the crude chloroform extract of $C$. asiatica exhibited the maximum inhibitory activity in-vitro. The crude chloroform extract of $C$. asiatica showed antibacterial activity only against $E$. tarda. On the other hand, A. hydrophila was unaffected by any of the crude extracts even at a level of $50 \mu \mathrm{L}$. The agar overlay well-diffusion assay with crude chloroform extract of C. asiatica yielded the highest zone of inhibition (30.50 \pm $6.40 \mathrm{~mm}$ ), which was comparable to those of the chloramphenicol $(40.75 \pm 1.76 \mathrm{~mm})$. This observation is particularly noteworthy because plants extracts are known to be more active against Gram-positive than Gram-negative bacteria possibly due to the structural difference in cell membrane [18]. The selective inhibitory effect of $C$. asiatica extract 
Citation: Purkait S, Abraham TJ, Karmakar S, Dey B, Roy A (2018) Inhibition of Fish Pathogenic Aeromonas hydrophila and Edwardsiella tarda by Centella asiatica In-vitro. J Aquac Res Development 9: 524. doi: 10.4172/2155-9546.1000524

among the bacterial strains tested could be attributed to the differences in outer membrane proteins of A. hydrophila and E. tarda [19]. In support of the present study, an earlier study observed significant zone of inhibition against Proteus vulgaris, Staphylococcus aureus, B. subtilis and Escherichia coli using the chloroform extract compared to aqueous extract [12]. Chloroform was found to be the most effective choice of solvent in inhibiting the growth of three strains of Salmonella compared to ethanol and hexane [13]. Similarly, the aqueous and acetone extracts were found to be less effective than the chloroform extract of leaf and callus of C. asiatica against the tested organisms [20]. They, however, noted that it was effective at the concentrations above $125 \mu \mathrm{g} / \mathrm{mL}$ against $S$. aureus and E. coli. The methanolic extract of $C$. asiatica of the present study had only weak inhibitory against $E$. tarda $(7.50 \pm 0.70 \mathrm{~mm})$. Contrarily, in an earlier study, the methanolic extract of C. asiatica showed no antibacterial activity against E. coli, Klebsiella pneumoniae and Pseudomonas aeruginosa [5]. Besides, several other studies demonstrated that the hexane and ethyl acetate extracts of $C$. asiatica inhibited the Gram-positive B. subtilis and Gram-negative $P$. aeruginosa, $P$. cichorii and E. coli in the disc diffusion test $[9,21]$. The lack of antimicrobial activity in the aqueous and methanolic extracts may be due to the absence of antimicrobial components in these extracts or the interference of pigments and phenolics with the antimicrobial activity of these extracts. The chloroform extract of $C$. asiatica was reportedly had higher concentration of phenol and its derivatives, ester, sesquiterpene and other miscellaneous compounds compared to hexane and ethanolic extracts [13]. An earlier study established a good correlation between the antibacterial activity and total phenolic content of plant extracts [22]. It has also been demonstrated that the activity of C. asiatica extract against the microorganisms is mainly concentrated in the triterpene asiaticoside. The triterpenes weaken the membranous tissues, which results in dissolving the cell walls of the microorganisms so that they can be more efficiently eliminated [11]. The anti-E. tarda activity of the chloroform extract of $C$. asiatica may be related to the presence of phenolic compounds, possibly triterpene asiaticoside. The qualitative UV-VIS spectrum profile of the chloroform extract of $C$. asiatica at a wavelength from 400 to $900 \mathrm{~nm}$ showed peaks at 677,542 and $443 \mathrm{~nm}$ with the absorption of $0.318,0.303$ and 0.301 respectively, which can serve as a baseline for future characterization of the extract. Considerable research has been carried out on the phytochemical properties of the plants, which have been amply reviewed $[4,9,20,22]$. It has been reported that the plant extracts consisted of triterpenoid glycosides, free acids, volatile oils and flavonoids [11]. The compounds such as alkaloids, glycosides, terpenoids, steroids, flavonoids, tannins and reducing sugars, etc have been identified in C. asiatica, which are known to possess antibacterial activities [20]. Centella asiatica has already been successfully used in controlling columnaris disease caused by Flavobacterium columnare without any inverse impact on fish [3]. Besides the antibacterial principles, C. asiatica reportedly possesses antifungal, anticancer, wound healing, neuroprotective, immunomodulatory, anti-inflammatory, hepatoprotective, insecticidal and antioxidant activities [9], which can be exploited for use in aquaculture as immunomodulators or as an alternative to antibiotics. This would reduce the over-dependence on antibiotics, whose use in aquaculture became a major concern from the public health point of view. In general, the results of this in-vitro study demonstrated that the chloroform extract of $C$. asiatica has antibacterial activity against $E$. tarda, a potent fish and zoonotic bacterial pathogen.

\section{Conclusion}

The current study accentuates the need for further research to identify the active compound(s) responsible for such anti-E. tarda activity and the exact mechanism of inhibition. The use of such medicinal plants is eco-friendly and cost-effective, which can be used in aquaculture health management and to address the issue of growing antibacterial resistance.

\section{References}

1. Harikrishnan R, Balasundaram C (2005) Modern trends in Aeromonas hydrophila disease management with fish. Rev Fish Sci 13: 281-320.

2. Wikipedia (2017a) Edwardsiella tarda. https://en.wikipedia.org/wiki/ Edwardsiella tarda. Accessed 14 Dec 2017

3. Rattanachaikunsopon P, Phumkhachorn P (2010) Use of Asiatic pennywort Centella asiatica aqueous extract as a bath treatment to control columnaris in Nile tilapia. J Aquat Anim Health 22: 14-20.

4. Al-Laham SA, Al-Fadel FM (2014) Antibacterial activity of various plants extracts against antibiotic-resistant Aeromonas hydrophila. Jundishapur $J$ Microbiol 7: 11370

5. Zaidan MR, Noor Rain A, Badrul AR (2005) In vitro screening of five local medicinal plants for antibacterial activity using disc diffusion method. Trop Biomed 22: 165-170.

6. Dhivya SM, Kalaichelvi K (2017) UV-VIS spectroscopic and FTIR analysis of Sarcostemma brevistigma, wight. and ARN. Int J Curr Pharm Res 9: 46-49.

7. Wikipedia (2017b) Centella asiatica. https://en.wikipedia.org/wiki/Centella asiatica. Accessed 14 Dec 2017.

8. Roy DC, Barman SK, Shaik MM (2013) Current updates on Centella asiatica: Phytochemistry, pharmacology and traditional uses. Med Plant Res 3: 20-36.

9. Agme-Ghodke V, Agmea RN, Sagarb AD (2016) Analysis of bioactive compounds in leaves extract of Centella asiatica by using HRLC-MS and IR techniques. J Chem Pharm Res 8: 122-125

10. Pitinidhipat N, Yasurin P (2012) Antibacterial activity of Chrysanthemum indicum, Centella asiatica and Andrographis paniculata against Bacillus cereus and Listeria monocytogenes under osmotic stress. AU J Technol 15: 239-245

11. Mamtha B, Kavitha K, Srinivasan KK, Shivananda PG (2004) An in vitro study of the effect of Centella asiatica [Indian pennywort] on enteric pathogens. Indian J Pharmacol 36: 41.

12. Dash BK, Faruquee HM, Biswas SK (2011) Antibacterial and antifungal activities of several extracts of Centella asiatica L. against some human pathogenic microbes. Life Sci Med Res 2011: LSMR-35 :1-5.

13. Rattanakom S, Yasurin P (2015) Chemical profiling of Centella asiatica under different extraction solvents and its antibacterial activity, antioxidant activity. Orient J Chem 31: 2453-2459.

14. Haniffa MA, Kavitha K (2012) Antibacterial activity of medicinal herbs against the fish pathogen Aeromonas hydrophila. J Agricult Technol 8: 205-211.

15. Prabuseenivasan S, Jayakumar M, Ignacimuthu $S$ (2006) In vitro antibacterial activity of some plant essential oils. BMC Complement Altern Med 6: 39

16. Hockett KL, Baltrus DA (2017) Use of the soft-agar overlay technique to screen for bacterially produced inhibitory compounds. J Vis Exp 119: 55064.

17. Kumar M, Berwal JS (1998) Sensitivity of food pathogens to garlic (Allium sativum). J Appl Microbiol 84: 213-215.

18. Oyedeji OA, Afolayan AJ (2005) Chemical composition and antibacterial activity of the essential oil of Centella asiatica growing in South Africa. Pharm Biol 43: 249-252.

19. Aoki T, Holland BI (1985) The outer membrane proteins of the fish pathogens Aeromonas hydrophila, Aeromonas salmonicida and Edwardsiella tarda. FEMS Microbiol Lett 27: 299-305.

20. Sekar T, Ayyanar M, Pillai YJK (2011) Phytochemical screening and antibacterial activity of leaf and callus extracts of Centella asiatica. Bangladesh J Pharmacol 6: 55-60.

21. European Scientific Cooperative on Phytotherapy [ESCOP] (2003) ESCOP Monographs: The Scientific Foundation for Herbal Medicinal Products. Thieme

22. Shan $B$, Cai $Y Z$, Brooks JD, Corke $H$ (2007) The in vitro antibacterial activity of dietary spice and medicinal herb extracts. Int J Food Microbiol 117: 112-119. 